\title{
Diagnosis and management of lumbar spinal stenosis in primary care in France: a survey of general practitioners
}

Marie-Ombeline Chagnas ${ }^{1}$, Serge Poiraudeau ${ }^{1,2,3,4^{\wedge}}$, Marie-Martine Lefèvre-Colau ${ }^{1,2,3,4}$, François Rannou ${ }^{1,2,5}$ and Christelle Nguyen ${ }^{1,2,5^{*}}$

\begin{abstract}
Background: Lumbar spinal stenosis (LSS) is a common spinal condition and the most frequent indication for spinal surgery in elderly people. General practitioners (GPs) are on the $1^{\text {st }}$ line for its diagnosis and treatment. We aimed to assess how GPs diagnose and treat people with LSS in France.

Methods: We conducted a cross-sectional survey in a primary care setting. French GPs were selected by a random draw from the French Medical Board. The questionnaire was designed by 3 physicians specialized in physical and rehabilitation medicine and a resident in general practice. A provisional questionnaire was tested in a pilot survey of 11 French GPs. Participants' feedbacks served to build the final questionnaire. This latter was submitted by e-mail or mail to 330 GPs. GPs were surveyed about the 3 main domains relevant to the management of people with LSS in primary care: 1/ diagnosis, 2/ pharmacological treatments and 3/ non-pharmacological treatments, using selfadministered open- and closed-ended questions and visual analog scales.
\end{abstract}

Results: Overall, 90/330 (27.3\%) GPs completed the survey. 51/89 (57.3\%) GPs were confident with managing people with LSS. Low back pain 51/87 (58.6\%), neurogenic claudication 38/87 (43.7\%) and paresthesia in the lower limbs 31/87 (35.6\%) were the 3 most frequently cited clinical signs leading to the diagnosis of LSS. Improvement with lumbar flexion was mentioned by 9/87 (10.3\%) GPs. 85/86 (98.8\%) would consider prescribing lumbar imaging, 60/84 (71.4\%) corticoid spinal injections and 42/79 (53.2\%) would never prescribe lumbar flexion-based endurance training. All GPs would refer people with LSS to another specialist.

Conclusions: French GPS lack confidence with diagnosing LSS and prescribing pharmacological and nonpharmacological treatments for people with LSS.

Keywords: Lumbar spinal stenosis, low back pain, neurogenic claudication, general practice

\section{Background}

Lumbar spinal stenosis (LSS) is a common spinal condition and the most frequent indication for spinal surgery in elderly people. The prevalence of LSS is estimated to be $9 \%$ in the general population and up to $47 \%$ in people

\footnotetext{
* Correspondence: christelle.nguyen2@aphp.fr

Serge Poiraudeau is deceased. This paper is dedicated to his memory.

'Assistance Publique-Hôpitaux de Paris, Rééducation et Réadaptation de l'Appareil Locomoteur et des Pathologies du Rachis, Hôpitaux Universitaires Paris Centre-Groupe Hospitalier Cochin, 27, Rue du Faubourg Saint-Jacques, 75014 Paris, France

${ }^{2}$ Université de Paris, Faculté de Santé, UFR Médecine, Sorbonne Paris Cité, 75006 Paris, France

Full list of author information is available at the end of the article
}

older than 60 years [1]. LSS may occur on a congenital narrow lumbar canal or may result from degenerative processes. Acquired LSS is secondary to facet joint osteoarthritis, ligamentum flavum hypertrophy and/or bulging of the intervertebral disc [2] and leads to the narrowing of the spaces around neurovascular structures of the spine [3]. LSS has a dynamic component: central stenosis increases in lumbar spine extension and decreases lumbar spine flexion [2]. Limitation in walking distance impacts patients' functioning and quality of life.

People with an anatomic LSS can remain asymptomatic for several years. Pain in the back and in the lower limbs is the most frequent symptom. The clinical sign

(c) The Author(s). 2019 Open Access This article is distributed under the terms of the Creative Commons Attribution 4.0 International License (http://creativecommons.org/licenses/by/4.0/), which permits unrestricted use, distribution, and reproduction in any medium, provided you give appropriate credit to the original author(s) and the source, provide a link to the Creative Commons license, and indicate if changes were made. The Creative Commons Public Domain Dedication waiver (http://creativecommons.org/publicdomain/zero/1.0/) applies to the data made available in this article, unless otherwise stated. 
most evocative of LSS is neurogenic claudication described as leg pain during walking, relieved by lumbar flexion or by sitting, while the association with low back pain (LBP) is inconsistent. Physicians usually consider a combination of clinical signs and imaging findings [3]. However, in an asymptomatic population, up to $20 \%$ of subjects have an imaging result consistent with anatomical LSS. Therefore a correlation between clinical signs and imaging findings is important to make the diagnosis and to offer the proper treatment [2]. The $1^{\text {st }}$-line treatment of LSS is conservative and includes analgesics, corticosteroid spinal injections, exercise therapy and physical activity [3]. Exercise therapy seems better than no treatment for leg pain $[4,5]$. However, evidence of efficacy of conservative treatment is of low quality.

GPs are on the $1^{\text {st }}$ line for the diagnosis and the management of musculoskeletal disorders, especially because they follow-up elderly people at long term and because elderly people are less eager to consult specialists than younger people [6, 7]. In 2017, 88,137 GPs were boardregistered in France. Most GPs did not receive a specific training in the management of musculoskeletal disorders. As a result, many lack confidence in the management of musculoskeletal disorders in daily practice [8]. Specific guidelines (such as those for LBP) may help GPs' decision-making in clinical practice. However, they are not fully implemented in primary care yet. A review published in 2016 by the Cochrane Collaboration suggested that training interventions or recommendations made by tertiary care specialists designed to promote behavioral changes and improve care were not appropriate for primary care, because they did not take into account the specific burden of primary care practice (e.g. lack of time, comorbidities) [8]. In the case of LSS, despite a high prevalence in elderly people, largely-disseminated diagnosis criteria and national or international guidelines are lacking.

In the present study, we aimed to assess how GPs diagnose and treat people with LSS in France.

\section{Methods \\ Design}

We conducted a cross-sectional survey of 330 French GPs. The results of our internet E-survey part were reported in accordance with the Checklist for Reporting Results of Internet E-Surveys (CHERRIES) [9] (Additional file 1).

\section{Participants}

Three hundred and thirty GPs of all 22 French regions, as distributed before 2015, were randomly drawn from the list of French Medical Board. GPs were contacted whether their activity was in private practice or hospital.

\section{Recruitment}

GPs were recruited from members of the French Medical Board. For each French region, 2 letters were first drawn by lot using the website www.dcode.fr. We obtained a list of 15 GPs per region. From January 8, 2018 to March 26, 2018, drawn GPs were contacted by phone. One investigator (MOC) presented the study and its purpose and collected the GP's email address. A link to the online questionnaire was sent by email on the same day. In case of refusal to participate or failure to reach the GP after 2 phone calls at 1-week interval, the GP was considered as non-respondent and the next GP in the list was contacted, and so on. Because of slow respondent accrual (26/170 [15.3\%] respondents) and high rates of contact failure (112/170 [65.9\%]), we decided to send a printed version of the questionnaire by mail to the remaining GPs on June 2018. The mailing included an information notice about the purpose of the study and a pre-addressed stamped envelope. GPs had 4 weeks to return the questionnaire and were considered as nonrespondents if they did not.

\section{Elaboration and content of the questionnaire}

A provisional questionnaire of 22 questions (Additional file 2) was elaborated by a panel of 3 physicians specialized in physical and rehabilitation medicine (PRM), from the Department of Rééducation et Réadaptation de l'Appareil Locomoteur et des Pathologies du Rachis from Cochin Hospital, Paris, France (SP, MMLC, CN), with over 10-year experience in the management of people with spinal conditions, and a resident in general practice (MOC). Informations about GPs' demographics (gender, date of medical residency, location), additional training in PRM, neurology or rheumatology and the approximate number of people with LSS they follow-up a year were collected. The questionnaire included self-administered open- and closed-ended questions, and rating of confidence for the diagnosis and management of LSS using self-administered visual analog scales (VAS). Items of the provisional questionnaire were classified into 3 domains relevant to the management of people with LSS in primary care: $1 /$ diagnosis, $2 /$ pharmacological treatments and 3/ non-pharmacological treatments. The provisional questionnaire was designed and made available online using SurveyMonkey (https://fr.surveymonkey.com/). A pilot survey was conducted from March 22, 2017 to May 23, 2017 to verify the relevance, acceptability, understanding and clarity of the questions in a randomly drawn sample of 11 GPs. The provisional questionnaire was modified according to their feedbacks to generate the final 22-item questionnaire (Additional file 3). Overall, we added questions about age, duration of practice and "Do you feel confident with the 
management of LSS?" and removed questions about the date of medical residency and evaluation of the questionnaire.

\section{Statistical analyses}

Quantitative variables were expressed as mean (SD) and qualitative variables as absolute frequency $(\mathrm{n} / \mathrm{N})$ and relative frequency (\%).

\section{Ethical consideration and funding statement}

According to the Jardé law (decree ${ }^{\circ} 2016-1537$ of November 16, 2016), regarding research involving humans and corresponding changes to the French Public Health Code, research aimed at evaluating the practice of health professionals or teaching practices in the field of health does not fall under the agreement of an institutional review board. All participants were informed orally or in writing by the investigator of the design and purpose of the study. For the purchase of stamps, we received a financial assistance by the association E.R.D.E « Études et Recherches sur le Développement de l'Enfant ». The funding body was neither involved in the design of the study, nor in collection, analysis, and interpretation of data and in writing the manuscript

\section{Results}

\section{Participants}

Overall, 192 GPs were contacted by phone from January 2018 to April 2018. The email address was obtained from 53/170 (31.2\%) GPs and 26/53 (49.1\%) GPs completed the online survey. In addition, 250 GPs (among whom 112 were first contacted by phone but did not respond) were contacted by mail in June 2018. 64/250
(25.6\%) GPs returned the printed version of the questionnaire (Fig. 1). 39/90 (43.3\%) GPs were women. Age was 48.3 (11.5) years and duration of practice was 18.4 (12.0) years. 4/90 (4.4\%) GPs received an additional training in PRM, rheumatology or neurology and 38/88 (43.2\%) followed less than 5 people with LSS a year (Table 1).

\section{Diagnosing people with LSS}

GPs rated their confidence with diagnosing people with LSS 5.6 (2.4) on a VAS (Table 2). LBP 51/87(58.6\%), neurogenic claudication $38 / 87(43.7 \%)$ and paresthesia in the lower limbs $31 / 87(35.6 \%)$ were the 3 most frequently cited clinical signs leading to the diagnosis of LSS. Improvement with lumbar flexion (shopping cart sign) was mentioned by only 9/87 (10.3\%) GPs (Fig. 2). 85/86 (98.8\%) would consider prescribing lumbar imaging: 54/ 86 (62.8\%) X-ray and CT-scan and 63/86 (73.3\%) MRI. "Other test" corresponded to electromyogram (Table 3).

\section{Prescribing pharmacological treatments}

GPs rated their confidence with prescribing pharmacological treatments 5.5 (2.5) on a VAS (Table 3). Overall, $53 / 82(64.6 \%)$ GPs would prescribe non-opioid analgesics and 56/85 (65.9\%) non-steroidal anti-inflammatory drugs (NSAIDs) in the $1^{\text {st }}$ line. Corticosteroid lumbar injections were never prescribed in the $1^{\text {st }}$ line. 19/84 (22.6\%) and 41/84 (48.8\%) GPs would prescribe them in the $2^{\text {nd }}$ or last lines, respectively. 23/84 (27.4\%) GPs would never prescribe corticosteroid injections and would rather leave this decision to a specialist (Fig. 3).

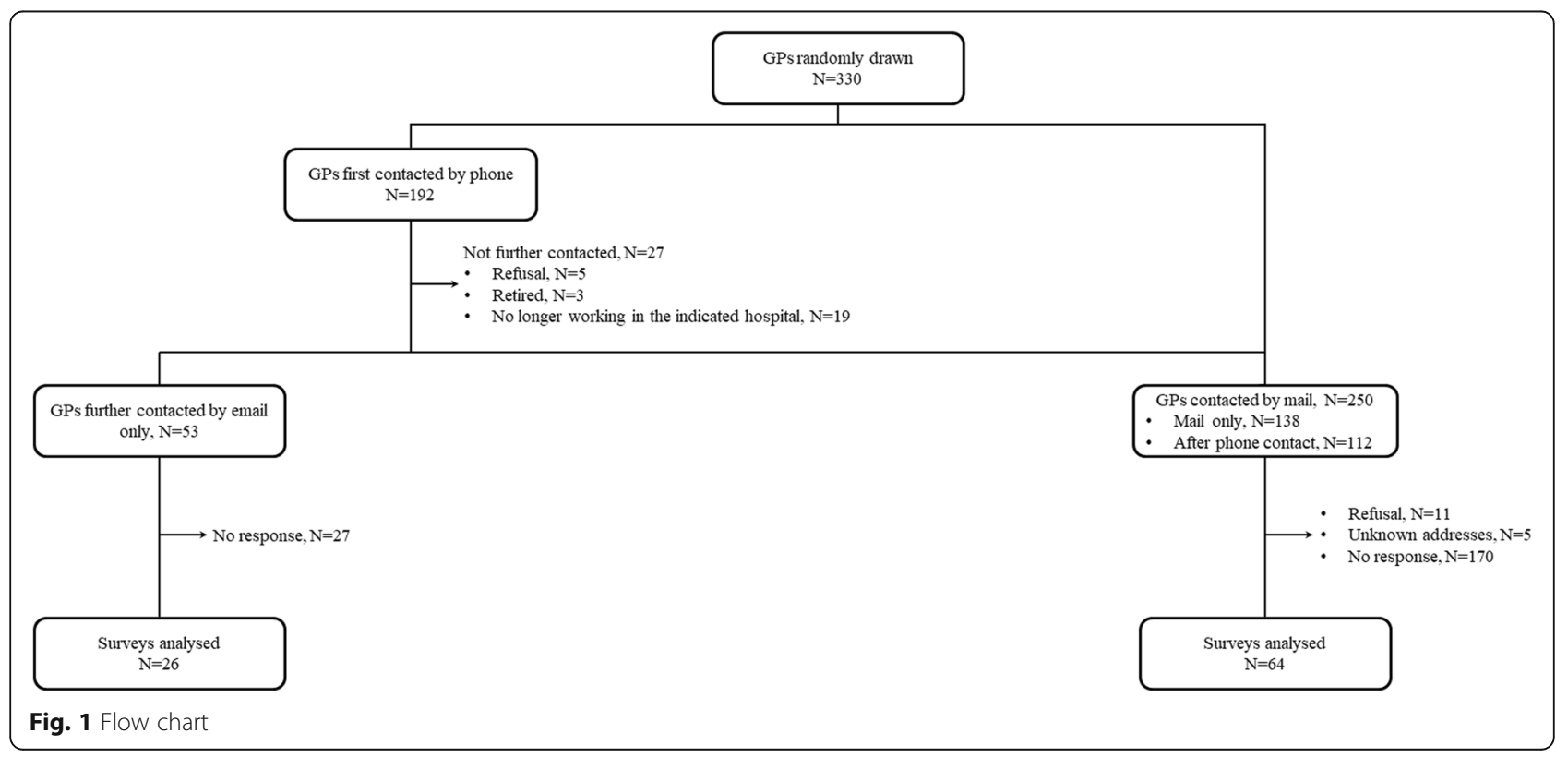


Table 1 Participants' demographics

\begin{tabular}{|c|c|}
\hline Women, n/N (\%) & $39 / 90(43.3)$ \\
\hline$\overline{\text { Mean age }(S D) \text {, years }}{ }^{\mathrm{a}}$ & $48.3(11.5)$ \\
\hline Mean duration of practice (SD), years ${ }^{a}$ & $18.4(12)$ \\
\hline \multicolumn{2}{|l|}{ Location of practice, n/N (\%) } \\
\hline Private practice & $43 / 90(47.8)$ \\
\hline Maison de Santé Pluriprofessionnelle & $22 / 90(24.4)$ \\
\hline Clinic & $1 / 90(1.1)$ \\
\hline Hospital & $13 / 90(14.4)$ \\
\hline Mixed practice (private and hospital) & $5 / 90(5.6)$ \\
\hline Other & $27 / 90(30.0)$ \\
\hline \multicolumn{2}{|l|}{ If hospital activity, specialty of the department } \\
\hline No hospital activity & $69 / 90(76.7)$ \\
\hline Emergency medicine & $6 / 90(6.7)$ \\
\hline Multidisciplinary department of medicine & 3/90 (3.3) \\
\hline Internal medicine & $1 / 90(1.1)$ \\
\hline Geriatric & 4/90 (4.4) \\
\hline PRM & $1 / 90(1.1)$ \\
\hline Other & $6 / 90(6.7)$ \\
\hline $\begin{array}{l}\text { Additional training in PRM, neurology or } \\
\text { rheumatology (yes), } \mathrm{n} / \mathrm{N}(\%)\end{array}$ & $4 / 90(4.4)$ \\
\hline \multicolumn{2}{|l|}{$\begin{array}{l}\text { Number of people with LSS followed-up a } \\
\text { year, n/N (\%) }\end{array}$} \\
\hline 0 & 12/88 (13.6) \\
\hline$<5$ & $38 / 88(43.2)$ \\
\hline $5-10$ & $23 / 88(26.1)$ \\
\hline $10-50$ & 14/88 (15.9) \\
\hline$>50$ & $1 / 88(1.1)$ \\
\hline
\end{tabular}

PRM Physical and Rehabilitation Medicine

${ }^{\mathrm{a}} \mathrm{N}=84$

\section{Prescribing non-pharmacological treatments}

GPs rated their confidence with prescribing nonpharmacological treatments 4.8 (2.6) on a VAS (Table 2). Overall, 65/83 (78.3\%) GPs would prescribe a lumbar belt and 77/82 (93.9\%) physiotherapy. 80/85 (94.1\%) GPs would consider prescribing physical activity. 42/79 (53.2\%) would never prescribe cycling and 32/79 (40.5\%) would never prescribe home-based exercises (Table 4). All GPs would refer people with LSS to a specialist: 69/

Table 2 Participants' confidence with the diagnosis and the management of people with LSS

$\begin{aligned} & \text { Do you feel confident with the management of LSS? } \\ & \text { (yes), n/N (\%) }\end{aligned}$
$\begin{aligned} & \text { Confidence with the diagnosis of people LSS (0-10), } \\ & \text { mean (SD) }\end{aligned}$
$\begin{aligned} & \text { Confidence with the pharmacological management } \\ & \text { of LSS (0-10), mean (SD) }\end{aligned}$
$\begin{aligned} & \text { Confidence with the non-pharmacological management } \\ & \text { of LSS (0-10), mean (SD) }\end{aligned}$

$85(81.2 \%)$ to an orthopedic surgeon, $52 / 85(61.2 \%)$ to a rheumatologist, $24 / 85(28.2 \%)$ to a specialist in PRM and $12 / 85(14.1 \%)$ to a neurologist (Table 5). 67/85 (78.8\%) GPs mentioned "analgesia" and 19/85 (22.4\%) "functional improvement" and "muscle strengthening" as the main goals of non-pharmacological treatments (Fig. 4). GPs would usually advise people with LSS to keep engaging in activities of daily living and physical activities (Fig. 5). 28/71 (39.4\%) GPs would recommend doing physical activity and only $1 / 71$ (1.4\%) to perform lumbar flexionbased exercises.

\section{Discussion}

Overall, French GPs lack confidence with diagnosing LSS and prescribing pharmacological and non-pharmacological treatments for people with LSS. Our findings may be explained by the lack of consensual national and international guidelines in primary care or of specific training during medical studies in France.

In our survey, GPs rated their confidence to diagnose people with LSS $5.6(2.4) / 10$. A set of clinical diagnosis criteria was proposed by the International Society for Study of the Lumbar Spine (ISSLS) in 2016. The 7 most relevant items according to the ISSLS were: 1/ leg or buttock pain while walking, 2/ flex forward to relieve symptoms, 3/ feel relief when using a shopping cart or a bicycle, 4/ motor or sensory disturbance while walking, 5/ pulses in the foot present and symmetric, 6/ lower extremity weakness, and 7/ LBP [1]. Recently, the NCLASS criteria were proposed for the diagnosis of neurogenic claudication caused by LSS [10]. This set includes: $1 /$ age $>60$ years, 2 / positive 30 -s extension test (typical leg symptoms reproduced during active spine extension performed in standing position for 30s), 3/ pain in both legs, 4/ leg pain relieved by sitting, 5/ leg pain decreased by leaning forward or flexing the spine, and 6/ negative SLR-60 test (Straight Leg Raise test: positive if leg pain is produced below $60^{\circ}$ ). In the present study, the clinical signs most frequently cited by French GPs differed from those included in these 2 published datasets. An explanation is that these datasets may lack applicability to primary care [11]. In the ISSLS study, GPs represented only $1 \%$ of participants and were not included in Genevay's survey. It would be interesting to build a set of specific LSS criteria by spine experts in collaboration with GPs, specifically designed to the constraints of primary care practice. In Japan, two diagnostic tools for LSS have been validated (the self-administrated, self-reported history questionnaire [SSHQ], and the developmental clinical diagnosis support tool [ST]). A survey evaluated the degree of awareness and use of these tools in 1,811 Japanese physicians [12]. Among GPs, the degree of awareness for both tools was less than 30\%, and their implementation ranged from 31 to $36 \%$. 


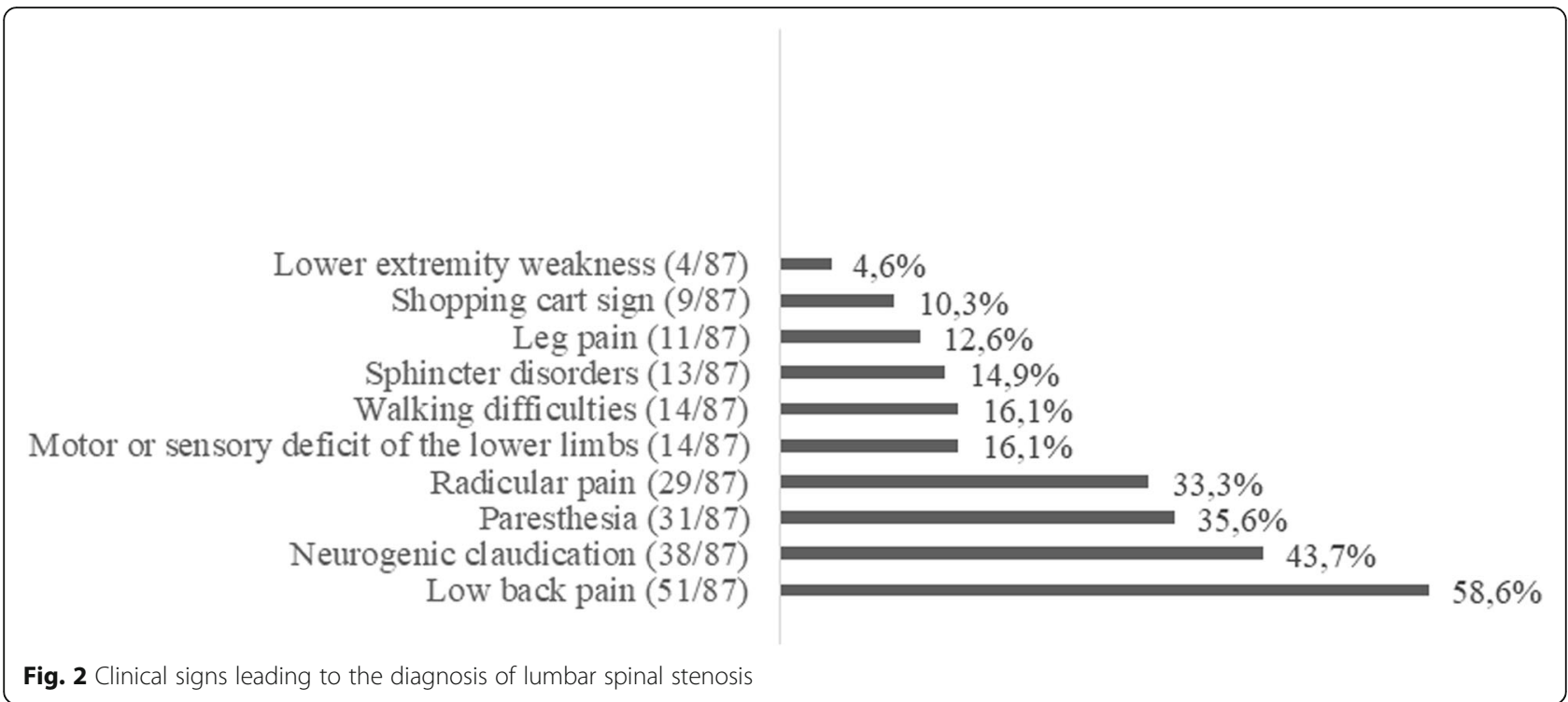

Improving the knowledge of validated diagnostic tools by practitioners could help to improve the management of LSS. In our study, 85/86 (98.8\%) of GPs would prescribe imaging, especially MRI (63/86 [73.3\%]). Imaging is often reserved for diagnostic confirmation, especially during pre-surgical evaluation [3]. MRI is the recommended test for confirming LSS [7]. A study showed $96 \%$ of sensitivity, $67 \%$ of specificity, $4 \%$ of positive predictive value and $100 \%$ of negative predictive value for the diagnosis of symptomatic LSS with MRI [13]. Electromyogram is not recommended [3] but can be used to rule out differential diagnosis in atypical symptoms [14].

LSS-related impairments are associated to activity limitation dominated by reduced pain free and maximal walking distances. In an interview of 33 patients with LSS, 88\% reported "experiencing pain/discomfort", 85\% "problems with physical function", 73\% "difficulty exercising" and $55 \%$ "difficulty participating in hobbies and leisure activities" [15]. Therefore, a combination of pharmacological and non-pharmacological treatments should be offered for an optimal management of people with LSS. In our survey, GPs rated their confidence with prescribing pharmacological treatments in people with LSS 5.5 (2.5)/10. Non-

Table 3 Prescription of imaging

\begin{tabular}{ll}
\hline Prescription of imaging (yes), $\mathrm{n} / \mathrm{N}(\%)$ & $85 / 86(98.8)$ \\
\hline Type of imaging prescribed, $\mathrm{n} / \mathrm{N}(\%)$ & \\
X-ray & $54 / 86(62.8)$ \\
CT-scan & $54 / 86(62.8)$ \\
MRI & $63 / 86(73.3)$ \\
Dynamic X-ray & $2 / 86(2.3)$ \\
Myelography & $2 / 86(2.3)$ \\
Other test & $5 / 86(5.8)$ \\
\hline
\end{tabular}

opioids analgesics and NSAIDs were prescribed as $1^{\text {st }}$-line treatments by most GPs. In a large cohort assessing the current treatment strategies by GPs for the management chronic pain of 1,379 elderly outpatients [6], prescriptions of analgesics by GPs followed national and international recommendations. However, in a population over 65 years, with comorbidities, these prescriptions must be limited in time [16]. Pregabalin and gabapentin have also been used. However, the efficacy of these drugs in people with LSS has not been proven yet. 69/81 (85.1\%) GPs would prescribe steroid injections. GPs who answered "other" indicated that this prescription was left to the specialist. Previous studies found limited evidence of a lack of effectiveness of epidural steroid injections in LSS [3]. In 2015, a meta-analysis showed the effectiveness of epidural corticosteroid injection, in a context of radiculopathy, on pain $(-7.55$ [95\%CI, -11.4 to 3.74$])$, function $(-0.33$ [CI, -0.56 to -0.09$])$ and surgery risk $(0.62[0.41$ to 0.92$])$ at short term. But no specific effect was shown in the treatment of LSS [17].

GPs rated their confidence with prescribing nonpharmacological treatments only $4.8(2.6) / 10$. Most GPs would advise their patients to practice a regular physical activity but not specifically cycling, a common modality of lumbar flexion-based exercises, or endurance training. Given the pathogenesis of neurogenic claudication in LSS related to the narrowing of the spinal canal in lumbar extension and its widening with the relief of the nerve root in lumbar flexion [18], a lumbar-flexionbased training program is usually recommended. In 2003, Iversen showed that a cycling program was feasible in a population of elderly people with LBP [19]. A recent pilot study [20] described the barriers (pain, fatigue, too large bicycle, burden of hospital follow-up, lack of time and motivation) and facilitators (clinical improvement, 


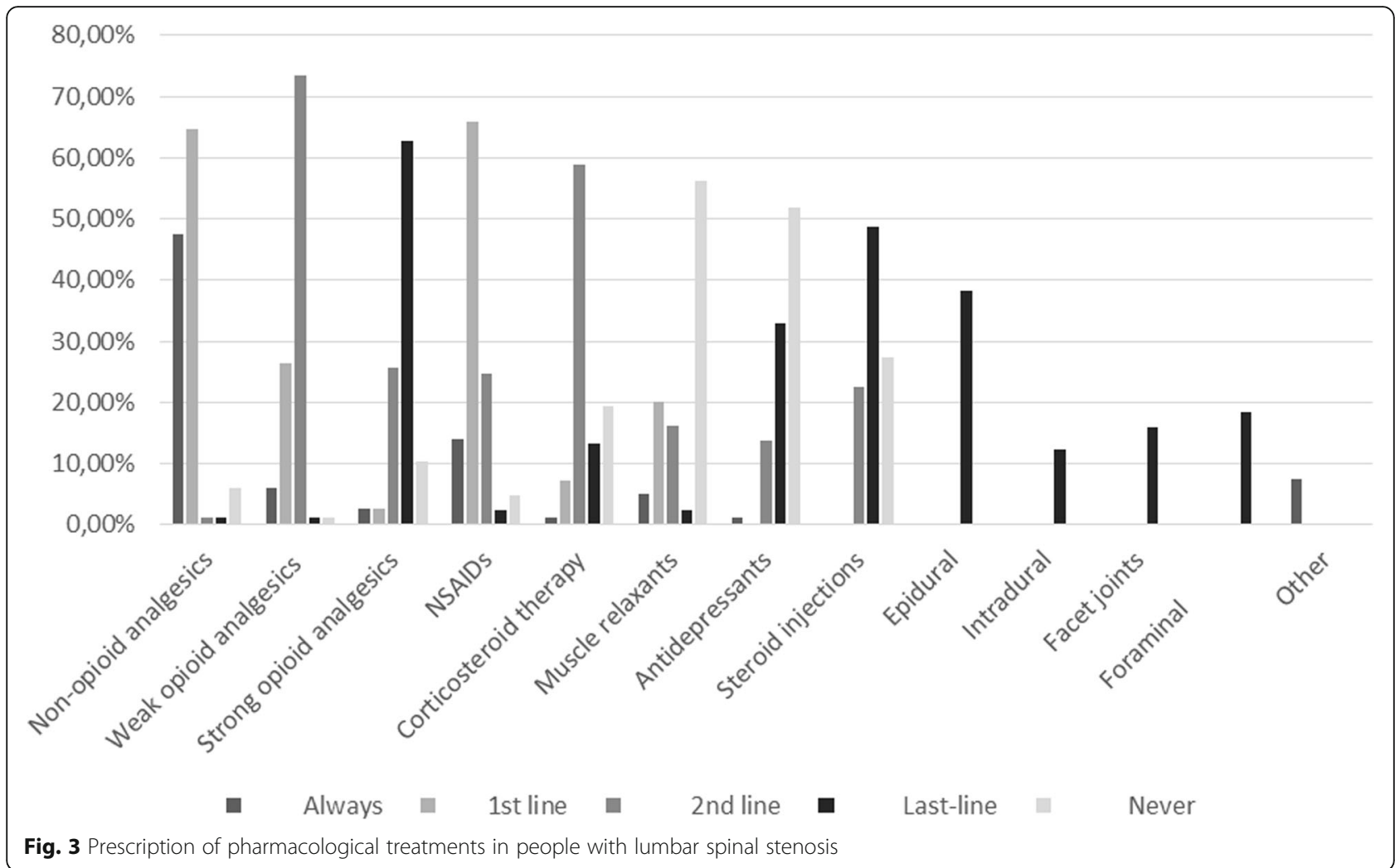

surveillance, ease-of-use) to home-based cycling in elderly people with LSS and found that adherence was stable over the 3-month follow-up. However, nearly all GPs $(77 / 82$ [93.9\%]) would refer people with LSS to a physiotherapist. An interpretation of this latter finding is that GPs would not pre-judge the non-pharmacological treatment to be prescribed but would rather leave that to the physiotherapists, which seems to be a reasonable therapeutic strategy.

Optimal health care journey of people with LSS is underreported in literature. In our survey, GPs would mostly refer their patients to a surgeon, suggesting that they would rather consider surgical than conservative treatment for people with LSS. A study assessing the management of LBP in primary care found similar results [21]: rheumatologists were consulted in 93\% and surgeons in $60 \%$. Several GPs reported that they would not refer their patients to a specialist in PMR because of the lack of accessibility to this specialty. In 2016, specialists in PMR were only 2,114 in France. A limitation of our survey on referral is that we did not specifically assess the potential relationship between reasons for referral and different specialists.

Several educational reasons may have contributed to the lack of confidence reported by French GPs with the management of people with LSS. During the $2^{\text {nd }}$ cycle of medical studies in France, LSS diagnosis and treatments are taught during rheumatology courses. In the reference textbook, only a short section is dedicated to LSS. Diagnosis and treatment key points could be summarized as

Table 4 Prescription of non-pharmacological treatments, n/N (\%)

\begin{tabular}{|c|c|c|c|c|c|}
\hline & Always & $1^{\text {st }}$ line & $2^{\text {nd }}$ line & Last-line & Never \\
\hline Lumbar brace & 11/83 (13.3) & 23/83 (27.7) & 30/83 (36.1) & 4/83 (4.8) & 18/83 (21.7) \\
\hline Physiotherapy & 27/82 (32.9) & 48/82 (58.5) & $9 / 82(11.0)$ & 2/82 (2.4) & $5 / 82(6.1)$ \\
\hline Balneotherapy & 10/83 (12.0) & 15/83 (18.1) & 43/83 (51.8) & 3/83 (3.6) & 16/83 (19.3) \\
\hline Spa therapy & $0 / 80(0.0)$ & 3/80 (3.8) & $22 / 80(27.5)$ & 19/80 (23.8) & $36 / 80(45.0)$ \\
\hline Cycling & $12 / 79(15.2)$ & 22/79 (27.8) & 9/79 (11.4) & $1 / 79(1.3)$ & $42 / 79(53.2)$ \\
\hline Physical activity & 43/85 (50.6) & $31 / 85(36.5)$ & 9/85 (10.6) & $2 / 85(2.4)$ & $8 / 85(9.4)$ \\
\hline Home-based exercises & 21/79 (26.6) & 19/79 (24.1) & 7/79 (8.9) & 0/79 (0.0) & $32 / 79(40.5)$ \\
\hline
\end{tabular}


Table 5 Referral to a specialist, n (\%)

\begin{tabular}{ll}
\hline Never & $0(0.0)$ \\
\hline In cases of diagnosis doubt & $29(34.1)$ \\
Upon evocation of diagnosis & $45(52.9)$ \\
In case of therapeutic failure & $46(54.1)$ \\
Other reason for referral & $8(9.4)$ \\
To which specialist ? & \\
$\quad$ Neurologist & $12(14.1)$ \\
Rheumatologist & $52(61.2)$ \\
Specialist of Physical and Rehabilitation Medicine & $24(28.2)$ \\
Orthopedic surgeon/ neurosurgeon & $69(81.2)$ \\
Other & $5(5.9)$ \\
\hline$N=85$ &
\end{tabular}

follows: $1 /$ average age is 60 years, $2 /$ clinical signs are pain increases in lumbar lordosis, paraesthesia, motor or sensory deficit, sphincter disorders, pain while walking and relieved by lumbar flexion (shopping cart sign), 3/ diagnosis is confirmed by MRI, and 4/ therapeutic options include symptomatic treatment, epidural steroid injections, lumbar flexion-based rehabilitation and surgery [22]. Residents in general practice do not receive a specific training for the management of elderly people with spinal disorders during the $3^{\text {rd }}$ cycle of medical studies. Furthermore, continuing medical education of GPs do not include specific training on the management of people with spinal disorders. In the present study, GPs reported they would be interested in receiving educational material on the management of LSS and the results of our survey.
Our study has limitations. The response rate was low but comparable to those reported from previous studies conducted in primary care [23]. Fundamental weakness are the purely descriptive nature of the report, the small sample size, and the low survey response rate which, while similar to other survey type studies, limits conclusions because of the high risk of bias in the survey. Our population of GPs was randomly selected from all over France, but we did not evaluate practices in other countries. Only volunteer GPs answered the questionnaire and one can assume that GPs feeling the least confident with the questionnaire may have not responded, which could have led to a selection bias and an overestimation of self-reported confidence scores. To assess GPs' confidence with prescribing pharmacological and non-pharmacological treatments for people with LSS, we used a self-administered VAS. However, there is no validated scale to assess this outcome. For example, in another study, participants were asked to rate their confidence with diagnosing the condition using a 5-class Likert scale ("definitely yes", "most likely", "likely", "not sure" and "definitely sure") [24]. The very low exposure to LSS in this sample is unexpected and certainly had an impact on our results. We can wonder whether there is confusion about the definition of LSS itself or whether LSS is underdiagnosed in primary care. Finally, because of slow accrual, we had to change the method of data collection after study commencement. Answers may have been different between participants who responded online and those who responded by mail.

$$
\begin{aligned}
& \text { To decrease pain (67/85) } \\
& \text { To improve functional recovery (19/85) } \\
& \text { To strengthen the muscles (19/85) } \\
& \text { To improve the functional autonomy . } \\
& \text { To release muscles (12/85) } \\
& \text { To fight against spinal stiffness (12/85) } \\
& \text { To improve the quality of life }(9 / 85) \\
& \text { To do phy sical activity }(6 / 85) \\
& 22,4 \% \\
& 22,4 \% \\
& 17,6 \% \\
& 4,1 \% \\
& 14,1 \% \\
& 10,6 \% \\
& \text { To decrease pharmacological treatment. } \\
& \text { To delay surgery }(4 / 85) \\
& 5,9 \% \\
& \text { To widen the spinal canal }(4 / 85) \\
& 4,7 \% \\
& 4,7 \%
\end{aligned}
$$

Fig. 4 Objectives of non-pharmacological treatments in people with lumbar spinal stenosis. Free text answers to the open-ended question "What are the 3 main objectives of non-pharmacological treatments in people with lumbar spinal stenosis?" were reviewed by the first and last authors. Answers were grouped when they were identical based on their opinion 
To do physical activity $(28 / 71)$

To continue activities of daily life (17/71)

To lose weight $(5 / 71)$

To walk $(4 / 71)$

To cycle $(2 / 71)$

To do kyphosis rehabilitation exercise $(1 / 71)$

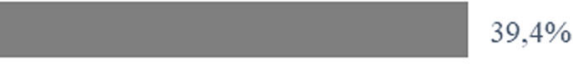

$23,9 \%$
$7,0 \%$

$5,6 \%$

$2,8 \%$

$1,4 \%$

Fig. 5 Advice given to people with lumbar spinal stenosis

\section{Conclusions}

Despite LSS is one of the most frequent spinal conditions in elderly people, French GPs lack confidence with its management in primary care. Our findings could be explained by the lack of national and international guidelines in primary care or of specific training in medical schools. Actions aiming at improving these aspects should be considered to improve health care of people with LSS.

\section{Additional files}

Additional file 1: Checklist for Reporting Results of Internet E-surveys (CHERRIES). (DOCX 21 kb)

Additional file 2: Provisional questionnaire. (DOCX $20 \mathrm{~kb}$ )

Additional file 3: Final questionnaire. (DOCX $20 \mathrm{~kb}$ )

\section{Abbreviations}

CHERRIES: Checklist for Reporting Results of Internet E-Surveys; GPs: general practitioners; LBP: Low back pain; LSS: Lumbar spinal stenosis; NRS: Numeric rating scale; PRM: Physical and rehabilitation medicine

\section{Acknowledgements}

The authors thank all the respondents to the survey.

\section{Authors' contributions}

Conception or design of the work: MOC, SP, MMLC, CN. acquisition, analysis or interpretation of data : MOC, SP, MMLC, CN. drafting the work or substantively revising it : MOC, MMLC, FR, CN. approval of the submitted version and any substantially modified version : MOC, MMLC, FR, CN. agree to be personally accountable for his/her own contributions and to ensure that questions related to the accuracy or integrity of any part of the work are appropriately investigated, resolved, and the resolution documented in the literature: MOC, MMLC, FR, CN. All authors read and approved the final manuscript.

\section{Authors' information}

Not applicable

\section{Funding}

For the purchase of stamps, we received a financial assistance by the association E.R.D.E « Études et Recherches sur le Développement de l'Enfant ». The funding body was neither involved in the design of the study nor in collection, analysis, and interpretation of data and in writing the manuscript.

Availability of data and materials

Data set available upon request from Associate Professor Christelle Nguyen (e-mail, christelle.nguyen2@aphp.fr).

Ethics approval and consent to participate

According to the Jardé law (decree n²016-1537 of November 16, 2016), regarding research involving humans and corresponding changes to the French Public Health Code, research aimed at evaluating the practice of health professionals or teaching practices in the field of health does not fall under the agreement of an institutional review board. All participants were informed orally or in writing by the investigator of the design and purpose of the study.

\section{Consent for publication}

Our manuscript does not contain any individual person's data in any form.

\section{Competing interests}

The authors declare that they have no competing interests.

\section{Author details}

${ }^{1}$ Assistance Publique-Hôpitaux de Paris, Rééducation et Réadaptation de I'Appareil Locomoteur et des Pathologies du Rachis, Hôpitaux Universitaires Paris Centre-Groupe Hospitalier Cochin, 27, Rue du Faubourg Saint-Jacques, 75014 Paris, France. Université de Paris, Faculté de Santé, UFR Médecine, Sorbonne Paris Cité, 75006 Paris, France. ${ }^{3}$ INSERM UMR 1153, Centre de Recherche Épidémiologie et Statistique Paris Sorbonne 75004 Cité, ECaMO Team, Paris, France. ${ }^{4}$ Institut Fédératif de Recherche sur le Handicap, 75013 Paris, France. ${ }^{5}$ NSSERM UMR 1124, Toxicité Environnementale, Cibles Thérapeutiques, Signalisation Cellulaire (T3S), Faculté des Sciences Fondamentales et Biomédicales, 75006 Paris, France.

Received: 10 February 2019 Accepted: 26 August 2019

Published online: 14 September 2019

\section{References}

1. Tomkins-Lane C, Melloh M, Lurie J, Smuck M, Battié MC, Freeman B, et al. ISSLS Prize Winner: Consensus on the Clinical Diagnosis of Lumbar Spinal Stenosis: Results of an International Delphi Study. Spine. 2016; 41(15):1239-46. 
2. Genevay S, Atlas SJ. Lumbar spinal stenosis. Best Pract Res Clin Rheumatol. 2010;24(2):253-65.

3. Lurie J, Tomkins-Lane C. Management of lumbar spinal stenosis. BMJ. 2016; 352:h6234.

4. Ammendolia C, Stuber K, Rok E, Rampersaud R, Kennedy CA, Pennick V, et al. Nonoperative treatment for lumbar spinal stenosis with neurogenic claudication. Cochrane Database Syst Rev. 2013;(8):CD010712.

5. Goren A, Yildiz N, Topuz O, Findikoglu G, Ardic F. Efficacy of exercise and ultrasound in patients with lumbar spinal stenosis: a prospective randomized controlled trial. Clin Rehabil. 2010;24(7):623-31.

6. Bertin P, Becquemont L, Corruble E, Derumeaux G, Falissard B, Hanon O, et al. The therapeutic management of chronic pain in ambulatory care patients aged 65 and over in France: the S.AGES Cohort. Baseline data. J Nutr Health Aging. 2013;17(8):681-6.

7. de Schepper EIT, Overdevest GM, Suri P, Peul WC, Oei EHG, Koes BW, et al. Diagnosis of lumbar spinal stenosis: an updated systematic review of the accuracy of diagnostic tests. Spine. 2013;38(8):E469-81.

8. Tzortziou Brown V, Underwood M, Mohamed N, Westwood O, Morrissey D. Professional interventions for general practitioners on the management of musculoskeletal conditions. Cochrane Database Syst Rev. 2016;(5):CD007495.

9. Eysenbach G. Improving the quality of Web surveys: the Checklist for Reporting Results of Internet E-Surveys (CHERRIES). J Med Internet Res. 2004;6(3):e34

10. Genevay S, Courvoisier DS, Konstantinou K, Kovacs FM, Marty M, Rainville J, et al. Clinical classification criteria for neurogenic claudication caused by lumbar spinal stenosis. The N-CLASS criteria. Spine J Off J North Am Spine Soc. 2018:18(6):941-7.

11. White KL, Williams TF, Greenberg BG. The ecology of medical care. N Engl J Med. 1961;265:885-92.

12. Ohtori S, Sekiguchi M, Yonemoto K, Kakuma T, Takahashi K, Konno S. Awareness and use of diagnostic support tools for lumbar spinal stenosis in Japan. J Orthop Sci Off J Jpn Orthop Assoc. 2014;19(3):412-7.

13. Aota Y, Niwa T, Yoshikawa K, Fujiwara A, Asada T, Saito T. Magnetic resonance imaging and magnetic resonance myelography in the presurgical diagnosis of lumbar foraminal stenosis. Spine. 2007;32(8): 896-903.

14. Kalff R, Ewald C, Waschke A, Gobisch L, Hopf C. Degenerative lumbar spinal stenosis in older people: current treatment options. Dtsch Arzteblatt Int. 2013;110(37):613-23 quiz 624.

15. Edwards TC, Lavallee DC, Bauer Z, Comstock BA, Jarvik JG, Patrick DL, et al. Problem areas identified as important to older adults with lumbar spinal stenosis. Spine J Off J North Am Spine Soc. 2015;15(7):1636-44.

16. Perrot $\mathrm{S}$. Management strategies for the treatment of non malignant chronic pain in the elderly. Psychol Neuropsychiatr Vieil. 2006;4(3):163-70.

17. Chou R, Hashimoto R, Friedly J, Fu R, Bougatsos C, Dana T, et al. Epidural Corticosteroid Injections for Radiculopathy and Spinal Stenosis: A Systematic Review and Meta-analysis. Ann Intern Med. 2015;163(5):373-81.

18. Penning $L$, Wilmink JT. Posture-dependent bilateral compression of $L 4$ or $L 5$ nerve roots in facet hypertrophy. A dynamic CT-myelographic study. Spine. 1987;12(5):488-500.

19. Iversen $M D$, Fossel $A H$, Katz JN. Enhancing function in older adults with chronic low back pain: a pilot study of endurance training. Arch Phys Med Rehabil. 2003;84(9):1324-31.

20. Pauwels $C$, Roren A, Gautier A, Linières J, Rannou F, Poiraudeau $S$, et al. Home-based cycling program tailored to older people with lumbar spinal stenosis: Barriers and facilitators. Ann Phys Rehabil Med. 2018;61(3):144-50.

21. Bouton $C$, Roche G, Roquelaure $Y$, Legrand E, Penneau-Fontbonne D, Dubus $\mathrm{V}$, et al. Management of low back pain in primary care prior to multidisciplinary functional restoration: a retrospective study of 72 patients. Ann Readapt Med Phys. 2008:51(8):650-6 656-62.

22. Les référentiels des Collèges - Collège français des enseignants en rhumatologie - Chapitre 4 - Item 93 - UE4 - Radiculalgie et syndrome canalaire.

23. Bonniaud V, Lyxuchouky X, Bévalot J, Decavel P, Metton G, Parratte B. Inquiry among general practitioners' knowledge regarding clean intermittent self-catheterization. Ann Readapt Med Phys. 2008;51(9):729-33.

24. Artus M, van der Windt DA, Afolabi EK, Buchbinder R, Chesterton LS, Hall A, et al. Management of shoulder pain by UK general practitioners (GPs): a national survey. BMJ Open. 2017;7(6):e015711.

\section{Publisher's Note}

Springer Nature remains neutral with regard to jurisdictional claims in published maps and institutional affiliations.

\section{Ready to submit your research? Choose BMC and benefit from:}

- fast, convenient online submission

- thorough peer review by experienced researchers in your field

- rapid publication on acceptance

- support for research data, including large and complex data types

- gold Open Access which fosters wider collaboration and increased citations

- maximum visibility for your research: over $100 \mathrm{M}$ website views per year

At $\mathrm{BMC}$, research is always in progress.

Learn more biomedcentral.com/submissions 